\title{
Analisa Potensi Bahaya dan Upaya Pencegahan Kecelakaan Kerja Dengan Job Safety Analisys (JSA) Pada Divisi Pencucian di PT "X"
}

\author{
Analysis of Potential Hazards and Work Accident Prevention Using Job Safety Analisys (JSA) \\ in Washing Division at " $X$ " Company
}

Siti Rohmah ${ }^{1 *}$, Kuswinarti

1,2Program Studi Teknik Tekstil, Politeknik STTT Bandung

\begin{abstract}
ARTICLE INFO
Article history:

DOI:

$\underline{10.30595 / p s p f s . v 11.133}$

Submitted:

June 25, 2021

Accepted:

July 10, 2021

Published:

Oct 31, 2021

ABSTRACT

The work process in the washing division of the "X" Company consists of three kinds of processes: washing, squeezing and drying. All of these work processes involve interactions between workers, raw materials, equipment and the environment. These interactions can create hazards and risks to both health and accident risks if they are not carried out according to the correct procedures and steps. The purpose of this study is to determine the potential hazards and risk rating in order to provide recommendations for their control in the washing division of the " $\mathrm{X}$ " Company. The research method is observational, which is only observing objects without controlling any variables. The steps taken are to identify and analyze the existing hazards and the risks that may occur so that analysis of potential hazards, types of accidents that may occur and recommendations for their control is needed. The research results show that the potential hazards in the washing division are 52, consisting of 46 ergonomic hazards and 6 chemical hazards. On this basis, recommendations for control have been prepared to prevent accidents that must be carried out.
\end{abstract}

Keywords:

JSA, Potential Hazard, Washing
This work is licensed under a Creative Commons Attribution 4.0 International License.

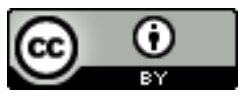

Corresponding Author:

Siti Rohmah

Program Studi Teknik Tekstil, Politeknik STTT Bandung

Jl. Jakarta No. 31 Bandung 40272 Telp. (022) 7272580 ext 109

Email: sitifirdaus2013@gmail.com

\section{PENDAHULUAN}

Peningkatan ilmu pengetahuan dan teknologi mempengaruhi dunia industri dalam melakukan efisiensi untuk meningkatkan produktivitas dengan menggunakan alat produksi yang semakin kompleks. Dampak positif dari penggunaan mesin berteknologi tinggi dapat memberikan kemudahan manusia dalam proses produksi dan produk yang dihasilkan akan maksimal tetapi mesin berteknologi tinggi dapat membahayakan, terlebih bagi karyawan/operator yang berpengetahuan kurang dan atau ceroboh, yang mana hal tersebut dapat menimbulkan kecelakaan kerja yang sangat fatal, yang kemudian disebut dengan bahaya kesehatan dan keselamatan kerja (Darisa, 2012).

Di samping dari penggunaan mesin, bahaya kesehatan dan keselamatan kerja juga dapat dipengaruhi oleh kondisi lingkungan kerja yang tidak memenuhi standar atau syarat-syarat Kesehatan dan Keselamatan Kerja (K3). Sumber bahaya di tempat kerja dapat berupa bahaya fisik, bahaya kimia, bahaya biologis, bahaya psikologis, bahaya ergonomis serta tindakan manusia itu sendiri, yang mana hal tersebut merupakan penyebab terjadinya kecelakaan akibat kerja dan penyakit akibat kerja (Kuswana, 2015).

Berdasarkan data BPJS Ketenagakerjaan pada 2019 terdapat 114 ribu kasus kecelakaan kerja, dan pada 2020 kasus tersebut terjadi peningkatan. Pada rentang Januari hingga Oktober 2020, BPJS Ketenagakerjaan mencatat 
terdapat 177 ribu kasus kecelakaan kerja (Detik.com, 2020). Hal ini menunjukan bahwa potensi bahaya yang menyebabkan kecelakaan kerja tersebut dapat berasal dari bebagai kegiatan atau aktivitas dalam pelaksanaan operasi atau juga berasal dari luar proses kerja (Tarwaka,2008)

Kecelakaan kerja merupakan suatu kejadian atau peristiwa tidak diinginkan yang menimbulkan kerugian terhadap manusia, kerugian terhadap proses, maupun merusak harta benda yang terjadi di dalam suatu proses kerja industri. Kejadian kecelakaan kerja terjadi akibat serangkaian peristiwa atau faktor-faktor sebelumnya, dimana jika salah satu bagian dari peristiwa atau faktor-faktor tersebut dihilangkan maka kejadian kecelakaan kerja tidak terjadi. Penyebab kecelakaan kerja digolongkan menjadi dua, yaitu unsafe action dan unsafe condition. Unsafe action adalah tindakan atau perbuatan manusia yang tidak mematuhi asas keselamatan, misalnya tidak menggunakan safety belt pada saat melakukan pekerjaan di ketinggian. Sedangkan unsafe condition adalah keadaan lingkungan tempat kerja yang tidak aman, misalnya keadaan tempat kerja yang kotor dan berantakan (Putra, 2017).

Tingginya kasus kecelakaan kerja menunjukkan bahwa masih kurangnya kesadaran tenaga kerja maupun pihak perusahaan dalam hal menangani masalah kesehatan keselamatan kerja. Penerapan sistem manajemen risiko merupakan salah satu upaya yang bisa dilakukan untuk mengurangi dan atau menghilangkan risiko bahaya yang terdapat di tempat kerja. Oleh karena itu dibutuhkan suatu pengukuran risiko kecelakaan kerja dengan metode identifikasi bahaya yang bisa menganalisis dan mengidentifikasi Sistem Manajemen Keselamatan dan Kesehatan Kerja.

Menurut OSHA (2002) Job Safety Analysis adalah sebuah analisis bahaya pada suatu pekerjaan yaitu teknik yang memfokuskan pada tugas pekerjaan sebagai cara untuk mengidentifikasi bahaya sebelum terjadi sebuah insiden atau kecelakaan kerja. Memfokuskan pada hubungan antara pekerja, tugas, alat, dan lingkungan kerja. Idealnya adalah setelah dilakukannya identifikasi bahaya yang tidak dapat dikendalikan, tentunya akan diambil tindakan atau langkahlangkah untuk menghilangkan atau mengurangi bahaya ke tingkat risiko yang dapat diterima oleh pekerja.

Menurut Friend dan Kohn (2006), JSA dapat bermanfaat untuk mengidentifikasi dan menganalisa bahaya dalam suatu pekerjaan sehingga bahaya pada setiap jenis pekejaan dapat dicegah dengan tepat dan efektif. Kemudian JSA juga dapat membantu para pekerja agar dapat memahahi pekerjaan mereka dengan lebih baik, khususnya memahami potensi bahaya yang ada dan dapat terlibat langsung untuk mengembangkan prosedur pencegahan kecelakaan. Hal ini membuat para pekerja dapat berpikir bahwa hasil yang melibatkan tentang keselamatan terkait pekerjaan itu tidak bisa disepelekan

PT "X" adalah perusahaan yang bergerak di bidang industri pakaian jadi dan menghasilkan brand sendiri yaitu Watchout dan Triset. Produk yang dihasilkan oleh PT "X" berupa pakaian kasual seperti kemeja, blouse, celana, kaos polo, dan jaket. Brand Watchout untuk laki laki dan Triset untuk perempuan.

Proses kerja di divisi pencucian PT "X" melibatkan interaksi antara pekerja, bahan baku, peralatan dan lingkungan. Interaksi tersebut dapat menimbulkan bahaya dan risiko baik risiko kesehatan maupun risiko kecelakaan jika tidak dilakukan sesuai prosedur dan langkah yang benar. Penelitian analisis potensi bahaya dilakukan untuk mengetahui bahaya dan tingkat risiko yang ada. Untuk mengetahui tingkatan risiko yang ada maka langkah awal yang harus dilakukan adalah mengidentifikasi dan menganalisis bahaya yang ada dan risiko yang mungkin terjadi sehingga dibutuhkan analisis potensi bahaya, jenis kecelakaan yang mungkin terjadi dan rekomendasi pengendaliannya.Tujuan penelitian ini adalah mengetahui potensi bahaya dan tingkat risiko untuk kemudian memberikan rekomendasi pengendaliannya di divisi pencucian PT "X".

\section{METODE PENELITIAN}

Jenis penelitian ini bersifat observasi, peneliti hanya mengamati subjek tanpa mengendalikan variabel apapun. Observasi dilakukan terhadap terhadap alat / mesin, material / bahan, sikap pekerja dan langkah langkah kerja dengan menggunakan metode Job Safety Analysis (JSA) untuk mengetahui potensi bahaya dan kecelakaan kerja pada proses washing di PT "X".

Lokasi penelitian dilakukan di PT "X", sebuah industri yang bergerak di bidang garmen yang beralamat di Jalan Cisirung Kota Bandung Jawa Barat, khususnya seluruh proses kerja pada divisi pencucian yang meliputi proses pencucian, pemerasan dan pengeringan.

Sumber data dalam penelitian ini meliputi sumber data primer dan data sekunder. Sumber data primer dalam penelitian ini didapatkan melalui observasi, wawancara, diskusi dan dokumentasi. Sedangkan untuk sumber data sekunder diperoleh dari data profil perusahaan.

Teknik pengambilan data yang digunakan dalam penelitian ini adalah melalui pengisisan worksheet Job Safety Analysis. Penilaian risiko dilakukan dengan berpedoman pada skala Australian Standard/New Zealand Standard for Risk Management (AS/NZS 4360:2004). Selain itu Teknik pengambilan data juga dilakukan melalui dokumentasi untuk melengkapi atau menguatkan data yang diperoleh dari hasil pengisian woorsheet dan observasi. Teknik analisis risiko yang digunakan menggunakan perhitungan risiko berdasarkan persamaan dari W. T. Fine (1971). Pada persamaan matematika Fine tersebut, terdapat tiga komponen yang digunakan dalam melakukan perhitungan nilai risiko, yaitu, kemungkinan terjadinya kecelakaan (probability)), dampak terjadinya risiko (consequence) dan 
frekuensi terjadinya kejadian (exposure). Untuk menentukan tingkat resiko maka dilakukan pengalian terhadap ketiga komponen risiko tersebut berdasarkan persamaan (1) berikut:

$$
\text { Risk }=\text { Consequences } x \text { Exposure } x \text { Probability }
$$

Nilai yang digunakan untuk tingkat dampak (consequence), frequensi (exposure) dan kemungkinan (probability) dapat dilihat pada Tabel 1, Tabel 2, dan Tabel 3. Dari hasil perhitungan level of risk kemudian akan dikelompokkan sesuai dengan nilai yang ada pada Tabel 4.

Tabel 1. Kriteria dan Nilai dari Faktor Cosequence Semi Kuantitatif

\begin{tabular}{|c|c|c|}
\hline Kategori & Deskripsi & Rating \\
\hline Catastropic & Bencana besar (kerusakan fatal/parah dari beragam fasilitas, aktivitas dihentikan) & 100 \\
\hline Disaster & $\begin{array}{l}\text { Bencana (kejadian yang berhubungan dengan kematian, kerusakan permanen yang } \\
\text { bersifat kecil terhadap lingkungan) }\end{array}$ & 50 \\
\hline Very Serious & $\begin{array}{l}\text { Sangat serius (terjadi cacat permanen/penyakit parah yang permanen, sedikit } \\
\text { berakibat buruk bagi lingkungan) }\end{array}$ & 25 \\
\hline Serious & $\begin{array}{l}\text { Serius (terjadi dampak yang serius tapi bukan cidera dan penyakit parah yang } \\
\text { permanen, sedikit berakibat buruk bagi lingkungan) }\end{array}$ & 15 \\
\hline Important & $\begin{array}{l}\text { Penting (membutuhkan penanganan medis, terjadi emisi buangan, di luar lokasi } \\
\text { tetapi tidak menimbulkan kerusakan) }\end{array}$ & 5 \\
\hline Noticeable & $\begin{array}{l}\text { Tampak (terjadi cidera atau penyakit ringan, memar pada bagian tubuh, kerusakan } \\
\text { kecil, kerusakan ringan dan terhentinya proses kerja sementara }\end{array}$ & 1 \\
\hline
\end{tabular}

Tabel 2. Kriteria dan Nilai dari Faktor Exposure Semi Kuantitatif

\begin{tabular}{llc}
\hline \multicolumn{1}{c}{ Kategori } & \multicolumn{1}{c}{ Deskripsi } & Rating \\
\hline Continously & Sering sekali: sering terjadi pemaparan dalam sehari & 10 \\
Frequently & Sering: Terjadi dalam sehari & 6 \\
Occasionally & Kadang-kadang: kadang-kadang, 1x seminggu, 1x sebulan & 3 \\
Infrequent & Satu kali dalam sebulan sampai sekali dalam setahun & 2 \\
Rare & Jarang diketahui kapan terjadinya & 1 \\
Very rare & sangat jarang: Tidak diketahui kapan terjadinya & 0,5 \\
\hline
\end{tabular}

Sumber: AS/NZS 4360:2004 Risk Management

Tabel 3. Kriteria dan Nilai dari Faktor Probability Semi Kuantitatif

\begin{tabular}{llc}
\hline \multicolumn{1}{c}{ Kategori } & \multicolumn{1}{c}{ Deskripsi } & Rating \\
\cline { 1 - 2 } Almost Certain & Sering terjadi: Kejadian kecelakaan yang paling sering terjadi & 10 \\
Likely & kemungkinan terjadinya kecelakaan 50\%-50\% & 6 \\
Unusual but possible & Tidak biasa: tidak biasa terjadi namun mempunyai kemungkinan terjadi & 3 \\
Remotely Possible & Kemungkinan kecil: kejadian yang kecil kemungkinannya terjadi & 2 \\
Conceivable & Jarang terjadi: tidak pernah terjadi kecelakaan selama bertahun-tahun & 0,5 \\
& pemaparan namun mungkin saja terjadi & 0,1 \\
Practically Impossible & Hampir tidak mungkin terjadi: sangat tidak mungkin terjadi & \\
\hline
\end{tabular}

Sumber: AS/NZS 4360:2004 Risk Management Guideline

Tabel 4. Tingkat Risiko pada Analisis Semi-Kuantitatif

\begin{tabular}{cll}
\hline Tingkatan & \multicolumn{1}{c}{ Deskripsi } & \multicolumn{1}{c}{ Tindakan } \\
\hline$>350$ & Very high & Stop aktivitas sampai risiko dikurangi \\
$180-350$ & Priority 1 & Membutuhkan Tindakan perbaikan segera \\
$70-180$ & Substantial & Membutuhkan Tindakan perbaikan \\
$20-70$ & Priority 3 & Membutuhkan perhatian dan pengawasan \\
$<20$ & Acceptable & Intensitas kegiatan yang menimbulkan risiko dikurangi seminimal mungkin \\
\hline
\end{tabular}

Sumber: AS/NZS 4360:2004 Risk Management Guideline

\section{HASIL DAN PEMBAHASAN}

Berdasarkan hasil observasi dan pengisian worksheet yang telah dilakukan pada masing-masing proses hasil penilaian risiko divisi pencucian PR "X" dapat dilihat pada Tabel 5 berikut ini: 
Tabel 5. Hasil Penilaian Resiko di Divisi Washing PT " $\mathrm{X}$ "

\begin{tabular}{|c|c|c|c|c|c|c|c|}
\hline \multirow{2}{*}{ No. } & \multirow{2}{*}{ Tahapan Pekerjaan } & \multirow{2}{*}{ Dampak } & \multicolumn{3}{|c|}{ Analisa Risiko } & \multirow{2}{*}{$\begin{array}{c}\text { Nilai } \\
\text { Risiko }\end{array}$} & \multirow{2}{*}{$\begin{array}{c}\text { Level } \\
\text { Risiko }\end{array}$} \\
\hline & & & $\mathbf{C}$ & $\mathbf{E}$ & $\mathbf{P}$ & & \\
\hline \multicolumn{8}{|c|}{ Proses Pencucian } \\
\hline 1 & \multirow{4}{*}{$\begin{array}{l}\text { Mengambil pakaian per artikel } \\
\text { dari rak penyimpanan ke dalam } \\
\text { keranjang }\end{array}$} & Terjatuh & 3 & 2 & 5 & 30 & Priority 3 \\
\hline 2 & & Terpeleset & 3 & 2 & 5 & 30 & Priority 3 \\
\hline 3 & & Cedera kaki & 3 & 0,5 & 1 & 7 & Priority 3 \\
\hline 4 & & Cedera tangan & 3 & 0,5 & 1 & 7 & Acceptable \\
\hline 5 & \multirow{3}{*}{$\begin{array}{l}\text { Menarik Keranjang menuju mesin } \\
\text { cuci }\end{array}$} & Tangan terluka & 6 & 2 & 1 & 13 & Acceptable \\
\hline 6 & & Terpeleset & 6 & 3 & 1 & 18 & Acceptable \\
\hline 7 & & Cedera kaki & 0,5 & 0,5 & 1 & 0,25 & Acceptable \\
\hline 8 & \multirow[t]{2}{*}{ Mengisikan air pada mesin cuci } & Iritasi kulit & 6 & 10 & 1 & 60 & Priority 3 \\
\hline 9 & & Tersengat listrik & 0,5 & 0,5 & 5 & 1,25 & Acceptable \\
\hline 10 & \multirow[t]{4}{*}{ Membuat larutan pencuci } & $\begin{array}{l}\text { Gangguan saluran } \\
\text { pernapasan }\end{array}$ & 10 & 10 & 15 & 1500 & Very high \\
\hline 11 & & Iritasi kulit & 10 & 10 & 1 & 100 & Substantial \\
\hline 12 & & Iritasi mata & 10 & 10 & 5 & 500 & Very high \\
\hline 13 & & keracunan & 0,5 & 0,5 & 5 & 1,25 & Acceptable \\
\hline 14 & \multirow[t]{4}{*}{ Memasukkan larutan pencuci } & Terpeleset & 1 & 2 & 1 & 2 & Acceptable \\
\hline 15 & & Nyeri otot tangan & 3 & 0,5 & 1 & 1,5 & Acceptable \\
\hline 16 & & Iritasi mata & 1 & 2 & 15 & 30 & Substantial \\
\hline 17 & & Iritasi kulit & 6 & 6 & 1 & 36 & Substantial \\
\hline 18 & \multirow{3}{*}{$\begin{array}{l}\text { Memasukan pakaian kedalam } \\
\text { mesin pencuci }\end{array}$} & Cedera kaki & 3 & 0,5 & 1 & 1,5 & Acceptable \\
\hline 19 & & Cedera kepala & 3 & 2 & 1 & 6 & Acceptable \\
\hline 20 & & Nyeri otot & 3 & 6 & 1 & 18 & Acceptable \\
\hline 21 & \multirow[t]{2}{*}{ Menekan tombol ON pada mesin } & Tersengat listril & 1 & 0,5 & 1 & 0,5 & Acceptable \\
\hline 22 & & Kerusakan mesin & 1 & 0,5 & 5 & 2,5 & Acceptable \\
\hline 23 & \multirow[t]{2}{*}{ Menekan tombol OFF pada mesin } & Tersengat listril & 1 & 0,5 & 1 & 0,5 & Acceptable \\
\hline 24 & & Kerusakan mesin & 1 & 0,5 & 5 & 2,5 & Acceptable \\
\hline 25 & \multirow{2}{*}{$\begin{array}{l}\text { Mengeluarkan pakaian dari mesin } \\
\text { dan memasukkan ke dalam } \\
\text { keranjang }\end{array}$} & Cedera tangan & 6 & 2 & 1 & 12 & Acceptable \\
\hline 26 & & Nyeri otot & 10 & 10 & 1 & 100 & Substantial \\
\hline
\end{tabular}

\section{Proses Pemerasan}

\begin{tabular}{|c|c|c|c|c|c|c|c|}
\hline 27 & \multirow{3}{*}{$\begin{array}{l}\text { Memasukkan pakaian ke dalam } \\
\text { mesin centrifugal }\end{array}$} & Tersengat listrik & 1 & 0,5 & 1 & 0,5 & Acceptable \\
\hline 28 & & Nyeri otot & 10 & 3 & 1 & 30 & Priority 3 \\
\hline 29 & & Iritasi kulit & 10 & 3 & 1 & 30 & Priority 3 \\
\hline 30 & \multirow{2}{*}{$\begin{array}{l}\text { Meratakan pakaian di dalam } \\
\text { mesin centrifugal }\end{array}$} & Nyeri otot & 3 & 3 & 1 & 9 & Acceptable \\
\hline 31 & & Cedera lengan & 3 & 2 & 1 & 6 & Acceptable \\
\hline 32 & Menekan tombol ON & Tersengat listrik & 1 & 0,5 & 1 & 0,5 & Acceptable \\
\hline 33 & \multirow{2}{*}{$\begin{array}{l}\text { Meratakan pakaian di dalam } \\
\text { mesin centrifugal }\end{array}$} & Cedera jari & 6 & 3 & 1 & 18 & Acceptable \\
\hline 34 & & Cedera lengan & 6 & 2 & 1 & 12 & Acceptable \\
\hline 35 & \multirow[t]{2}{*}{ Menekan tombol OFF } & Tersengat listrik & 1 & 0,5 & 1 & 0,5 & Acceptable \\
\hline 36 & & Kerusakan mesin & 0,5 & 0,5 & 2 & 0,5 & Acceptable \\
\hline 37 & \multirow{2}{*}{$\begin{array}{l}\text { Mengeluarkan cucian dari mesin } \\
\text { centrifugal }\end{array}$} & Iritasi kulit & 6 & 3 & 1 & 18 & Acceptable \\
\hline 38 & & Cedera tangan & 3 & 3 & 1 & 9 & Acceptable \\
\hline
\end{tabular}

\section{Proses Pengeringan}

\begin{tabular}{|c|c|c|c|c|c|c|c|}
\hline 39 & \multirow[t]{2}{*}{ Menarik keranjang cucian } & Iritasi kulit & 6 & 3 & 1 & 18 & Acceptable \\
\hline 40 & & Cedera tangan & 6 & 2 & 1 & 12 & Acceptable \\
\hline 41 & \multirow{2}{*}{$\begin{array}{l}\text { Memasukkan cucian kedalam } \\
\text { mesin pengering }\end{array}$} & Nyeri otot & 6 & 2 & 1 & 12 & Acceptable \\
\hline 42 & & Iritasi kulit & 6 & 3 & 1 & 18 & Acceptable \\
\hline 43 & \multirow[t]{2}{*}{ Menutup pinti mesin pengering } & Cedera lengan & 1 & 0,5 & 1 & 0,5 & Acceptable \\
\hline 44 & & Kerusakan mesin & 0,5 & 0,5 & 5 & 1,25 & Acceptable \\
\hline 45 & \multirow[t]{2}{*}{ Menekan tombol ON } & Tersengat listrik & 6 & 0,5 & 1 & 3 & Acceptable \\
\hline 46 & & Cedera tangan & 6 & 0,5 & 1 & 3 & Acceptable \\
\hline
\end{tabular}




\begin{tabular}{|c|c|c|c|c|c|c|c|}
\hline 47 & & Kerusakan mesin & 3 & 0,5 & 5 & 7,5 & Acceptable \\
\hline 48 & \multirow[t]{2}{*}{ Menekan tombol OFF } & Tersengat listrik & 0,5 & 0,5 & 1 & 0,5 & Acceptable \\
\hline 49 & & Kerusakan mesin & 0,5 & 0,5 & 5 & 1,25 & Acceptable \\
\hline 50 & \multirow{3}{*}{$\begin{array}{l}\text { Mengeluarkan pakaian dari mesin } \\
\text { dan memasukkan ke dalam } \\
\text { keranjang }\end{array}$} & Iritasi kulit & 10 & 10 & 1 & 100 & Substantial \\
\hline 51 & & Cedera tangan & 6 & 2 & 1 & 12 & Acceptable \\
\hline 52 & & Cedera kaki & 3 & 0,5 & 1 & 1,5 & Acceptable \\
\hline
\end{tabular}

Penilaian risiko yang dilakukan pada seluruh tahapan proses di divisi washing meliputi proses pencucian, pemerasan dan pengeringan. Dari hasil penenilaian tersebut ditemukan 52 macam risiko dengan rincian risiko pada kategori dapat diterima (acceptable) sebanyak 38 risiko (73,07\%), Priority 3 sebanyak 6 risiko (11,54\%), Substantial sebanyak 5 risiko $(9,62 \%)$ dan Very high sebanyak 1 risiko (1,92\%). Dilihat dari persentase tingkat risiko hampir sebagian besar berada pada tingkat <20 (acceptable) yang artinya intensitas kegiatan yang menimbulkan risiko dikurangi seminimal mungkin.

Berdasarkan penilaian tingkat risiko pada Tabel 5, maka dapat disususn rekomendasi pengendalian setiap tahapan langkah kerja sebagai upaya pencegahan dari dampak risiko kecelakaan kerja pada divisi pencucian di PT "X" yang dapat dilihat pada Tabel 6, Tabel 7 dan Tabel 8.

Tabel 6. Rekomendasi Pengendalian Dampak Risiko Kecelakaan Kerja Proses Pencucian

\begin{tabular}{|c|c|c|}
\hline No. & Langkah kerja & Rekomendasi Pengendalian \\
\hline 1. & $\begin{array}{l}\text { Mengambil pakaian per artikel dari rak } \\
\text { penyimpanan ke dalam keranjang }\end{array}$ & Menambah fasilitas alat bantu berupa tangga \\
\hline 2. & Menarik Keranjang menuju mesin cuci & $\begin{array}{l}\text { Menyediakan Alat Pelindung Diri (APD) berupa } \\
\text { sarung tangan dan penggantian sepatu booth secara } \\
\text { berkala }\end{array}$ \\
\hline 3. & Mengisikan air pada mesin cuci & Menyediakan APD berupa sarung tangan \\
\hline 4. & Membuat larutan pencuci & $\begin{array}{l}\text { Menyediakan APD berupa sarung tangan, masker, } \\
\text { dan kaca mata google } \\
\text { Melakukan training safety behaviour kepada pekerja } \\
\text { Memberi rambu tanda bahaya pada area yang } \\
\text { terkontaminasi bahan kimia }\end{array}$ \\
\hline 5. & Memasukkan larutan pencuci & $\begin{array}{l}\text { Memberi rambu tanda bahaya pada area washing } \\
\text { Melakukan perenggangan sebelum bekerja } \\
\text { Menyediakan APD berupa sarung tangan }\end{array}$ \\
\hline 6. & Memasukan pakaian kedalam mesin pencuci & $\begin{array}{l}\text { Alat bantu berupa kaki yang tinggi dan beroda pada } \\
\text { bawah keranjang. } \\
\text { Melakukan perenggangan sebelum mulai bekerja }\end{array}$ \\
\hline 7. & Menekan tombol ON pada mesin & $\begin{array}{l}\text { Menyediakan APD berupa sarung tangan } \\
\text { Memberi rambu tanda bahaya pada area washing }\end{array}$ \\
\hline 8. & Menekan tombol OFF pada mesin & $\begin{array}{l}\text { Menyediakan APD berupa sarung tangan } \\
\text { Melakukan training safety behaviour kenada nekeria }\end{array}$ \\
\hline 9. & $\begin{array}{l}\text { Mengeluarkan pakaian dari mesin dan } \\
\text { memasukkan ke dalam keranjang }\end{array}$ & $\begin{array}{l}\text { alat bantu berupa kaki yang tinggi dan beroda } \\
\text { sebagai alas pada bagian bawah keranjang } \\
\text { Melakukan perenggangan sebelum mulai bekerja }\end{array}$ \\
\hline
\end{tabular}

Tabel 7. Rekomendasi Pengendalian Dampak Risiko Kecelakaan kerja Proses Pemerasan

\begin{tabular}{|c|c|c|}
\hline No. & Langkah kerja & Rekomendasi Pengendalian \\
\hline 1. & $\begin{array}{l}\text { Memasukkan pakaian ke dalam mesin } \\
\text { centrifugal }\end{array}$ & $\begin{array}{l}\text { Menyediakan APD berupa sarung tangan karet (rubber } \\
\text { gloves) }\end{array}$ \\
\hline 2. & $\begin{array}{l}\text { Meratakan pakaian di dalam mesin } \\
\text { centrifugal }\end{array}$ & Menyediakan fasilitas APD berupa sarung tangan karet \\
\hline 3. & Menekan tombol ON & Memberi jeda kepada pekerja apabila pekerja kelelahan. \\
\hline 4. & $\begin{array}{l}\text { Meratakan pakaian di dalam mesin } \\
\text { centrifugal }\end{array}$ & $\begin{array}{l}\text { Membuat Standard Operating Procedure (SOP) pada mesin } \\
\text { centrifugal }\end{array}$ \\
\hline 5. & Menekan tombol OFF & $\begin{array}{l}\text { Menyediakan APD berupa sarung tangan karet (rubber } \\
\text { gloves) }\end{array}$ \\
\hline & & $\begin{array}{l}\text { Memberikan training safety behavior kepada pekerja } \\
\text { Melakukan perenggangan otot sebelum mulai bekeria }\end{array}$ \\
\hline 6. & $\begin{array}{l}\text { Mengeluarkan cucian dari mesin } \\
\text { centrifugal }\end{array}$ & \\
\hline
\end{tabular}


Tabel 8. Rekomendasi Pengendalian Dampak Risiko Kecelakaan kerja Proses Pengeringan

\begin{tabular}{|c|c|c|}
\hline No. & Langkah kerja & Rekomendasi Pengendalian \\
\hline 1. & Menarik keranjang cucian & $\begin{array}{l}\text { Membuat alat bantu kaki beroda sebagai alas } \\
\text { keranjang }\end{array}$ \\
\hline 2. & Memasukkan cucian kedalam mesin pengering & $\begin{array}{l}\text { Menyediakan fasilitas APD berupa sarung tangan } \\
\text { karet } \\
\text { Melakukan perenggangan otot sebelum bekerja }\end{array}$ \\
\hline 3. & Menutup pinti mesin pengering & $\begin{array}{l}\text { Memberi poster peringatan didekat pintu mesin } \\
\text { dryer }\end{array}$ \\
\hline 4. & Menekan tombol ON & $\begin{array}{l}\text { Menyesuaikan pekerja dengan jenis pekerjaan, } \\
\text { Melakukan service mesin secara teratur setiap } \\
\text { minggu }\end{array}$ \\
\hline \multirow[t]{3}{*}{5.} & Menekan tombol OFF & $\begin{array}{l}\text { Membuat Standard Operating Procedure (SOP) } \\
\text { untuk mesin dryer }\end{array}$ \\
\hline & & $\begin{array}{l}\text { Pelatihan kepada pekerja bagaimana cara bekerja } \\
\text { yang aman (safety behavior) }\end{array}$ \\
\hline & & $\begin{array}{l}\text { Menyediakan fasilitas APD berupa sarung tangan } \\
\text { karet }\end{array}$ \\
\hline \multirow[t]{2}{*}{6.} & $\begin{array}{l}\text { Mengeluarkan pakaian dari mesin dan } \\
\text { memasukkan ke dalam keranjang }\end{array}$ & $\begin{array}{l}\text { Menyediakan fasilitas APD berupa sarung tangan } \\
\text { karet }\end{array}$ \\
\hline & & Sikap tubuh yang benar \\
\hline
\end{tabular}

\section{KESIMPULAN}

Berdasarkan hasil pengamatan yang dilakukan pada divisi wpencucian PT "X" menggunakan Job Safety Analisys (JSA) dapat diketahui penenilaian risiko pada tiga proses pekerjaan ditemukan sebanyak 52 macam risiko dengan rincian risiko pada kategori dapat diterima (acceptable) sebanyak 38 risiko (73,07\%), Priority 3 sebanyak 6 risiko (11,54\%), Substantial sebanyak 5 risiko $(9,62 \%)$ dan Very high sebanyak 1 risiko (1,92\%).Berdasarkan penilaian tingkat risiko dapat disususn rekomendasi pengendalian sebagai upaya pencegahan dari dampak risiko kecelakaan kerja.

\section{UCAPAN TERIMA KASIH}

Ucapan terimakasih disampaikan kepada Direktur Politeknik STTT Bandung dan juga kepada Ketua Program Studi Teknik Tekstil atas kesempatan dan dukungan yang diberkan untuk mengikuti kegiatan seminat kali ini.

\section{DAFTAR PUSTAKA}

Australia Standard / New Zealand Standard. (2004). Australian Standard / New Zaeland Standard Risk Management 4360:2004. Sydney and Wellington: Author.

Darisa, A. (2012). Identifikasi Keselamatan dan Kesehatan Kerja (K3) dengan Metode Hazard Identification Risk Assessment Control (HIRAC) di PT. Campina Ice Cream Industry Surabaya. [Skripsi]. Surabaya: Program StudiTeknik Industri, Fakultas Teknik Industri, Universitas Pembangunan Nasional "Veteran”Jawa Timur

Friend, M.A. dan Kohn, J.P.,(2007). Fundamental of Occupational Safety and Helath. Fourth Edition. Government Institutes. Lanham, Maryland.Toronto.

Kuswana, W.S. (2015). Mencegah Kecelakaan Kerja. Bandung: PT. Remaja Rosdakarya

OSHA. (2002). Job Hazard Analysis (OSHA 3071 Revised). US. Departement of Labour.

Putra, D. P., 2017. Penerapan Inspeksi Keselamatan dan Kesehatan Kerja sebagai Upaya Pencegahan Kecelakaan Kerja. HIGEA, 1(1): 73-83

Tarwaka, (2008). Keselamatan dan Kesehatan Kerja. Surakarta : Harapan Press.

Fine, W.T. (1971) Mathematical Evaluations for Controlling Hazards. Journal of Safety Research, 3, 157-166.

https://finance.detik.com/berita-ekonomi-bisnis/d-5374660/kecelakaan-kerja-tinggi-menaker-dorongdunia-usaha-investasi-bidang-k3, diakses tanggal 9 Maret 2021, Pukul 14:56 